\title{
DO ESPAÇO DO SUJEITO AO ESPAÇO MUNDIAL: uma nova maneira de apreender a realidade
}

Márcio Carneiro dos Reis*

\begin{abstract}
Resumo: O trabalho procura dialogar com a obra de Boaventura de Souza Santos, mais exatamente sua contribuição contida em "A crítica da razão indolente: contra o desperdício da experiência". O que se propõe, principalmente com base em Norbert Elias, é a inclusão no Mapa da Estrutura-Ação das sociedades capitalistas no espaço mundial de outros dois espaços estruturais nele não contemplados: o espaço do sujeito e o espaço grupal. Argumentaremos que o indivíduo, tal como o conhecemos hoje, constitui-se numa instituição que nasceu com a modernidade. Esse, em função da possibilidade de diálogo que mantém consigo mesmo, enquanto sujeito, pode também ser percebido como um espaço estrutural, passivo da ação de forças de regulação e de emancipação social, discutidas por Boaventura. O grupo social, por sua vez, possui uma dinâmica própria, que não pode ser totalmente apreendida nem pelo espaço doméstico, nem pelo espaço da comunidade. Nesse sentido, a partir do que o autor chama de transição paradigmática, o trabalho analisa e expõe os traços principais de sua contribuição, para depois realizar uma breve incursão na Sociologia de Norbert Elias e propor a inclusão dos espaços do sujeito e do grupo como instâncias relevantes para a apreensão da realidade em movimento. Na conclusão, retomarse-á discussão inicial, procurando pôr em evidência não apenas o papel desses dois espaços estruturais propostos, bem como de todo o Mapa para a compreensão dos processos em curso e da construção de estratégias de transformação social.

Palavras-chave: transição paradigmática, mapa da estruturaação, sociologia, Norbert Elias, espaço do sujeito, espaço grupal.
\end{abstract}

* Mestre em Economia pela Universidade Federal de Minas Gerais (UFMG); Doutorando em Desenvolvimento, Agricultura e Sociedade na Universidade Federal Rural do Rio de Janeiro (CPDA/UFRJ); professor da Universidade de Itaúna-MG, da UEMG e do UNI-BH. Artigo recebido em 30 jun. 2003; aprovado em 30 ago. 2003. 


\section{Introdução}

O objetivo do trabalho é dialogar com a obra de Boaventura de Souza Santos, mais exatamente com sua contribuição, contida em A crítica da razão indolente: contra o desperdício da experiência. $\mathrm{O}$ que se propõe, principalmente com base em Norbert Elias, é a inclusão no Mapa da Estrutura-Ação de outros dois espaços estruturais nele não contemplados: o espaço do sujeito e o espaço grupal. Argumentaremos, no bojo da originalidade da contribuição de Santos, que o indivíduo, tal como o conhecemos hoje, constitui-se numa instituição que nasceu com a modernidade. Esse, em função da possibilidade de diálogo que mantém consigo mesmo, enquanto sujeito, pode também ser percebido como um espaço estrutural, passivo da ação de forças de regulação e de emancipação social, discutidas por Boaventura. O grupo social, por sua vez, possui uma dinâmica própria, que não pode ser totalmente apreendida nem pelo espaço doméstico, nem pelo espaço da comunidade. Além disso, com o avanço da modernidade, dos processos de urbanização e de impessoalização das relações sociais, o espaço grupal vem se tornando a referência maior para um grupo cada vez maior de pessoas.

Para tanto, precisamos, primeiro, evidenciar o contexto de crise paradigmática do qual parte o autor para, depois, expor e analisar os traços principais de sua contribuição, sobretudo aquela que informa a construção o Mapa da Estrutura-Ação das sociedades capitalistas no espaço mundial. Então, depois de fazermos uma breve incursão pela sociologia de Norbert Elias, discutiremos e proporemos a inclusão dos espaços do sujeito e do grupo como instâncias relevantes para a apreensão da realidade em movimento e, em conseqüência, para se pensar processos de transformação social.

\section{A crise paradigmática}

O último meio século foi palco de um conjunto de transformações sociais profundas, o que acabou por implicar a necessidade de se conceber, no contexto das ciências sociais, maneiras 
alternativas de se apreender a realidade, ainda não de todo desenvolvidas. No campo da ciência (Bourdieu, 2000), ${ }^{1}$ mais especificamente, parece existir uma posição dominante, oriunda da revolução newton-cartesiana dos séculos XVII e XVIII e que ainda carrega uma grande influência da herança iluminista. Sustentando uma postura metodológica essencialmente analítico-dedutiva, bem como positiva, pois que foi capaz de sintetizar o empirismo baconiano e o racionalismo cartesiano em torno do chamado método científico, habitus particular desse campo de disputa, essa posição se reproduziu e se legitimou em meio aos ataques sofridos provenientes de uma outra postura metodológica. Esta, por sua vez, também herdeira do racionalismo iluminista, adotou uma perspectiva dialética diante da realidade, privilegiando assim os processos históricos como instrumento de conhecimento, em detrimento da matemática e da estatística, característica da posição dominante.

No início do século XX, uma outra postura metodológica entrou também na disputa em torno desse campo, tendo ficado conhecida como a Teoria dos Sistemas (Capra, 1982; Vasconcelos, 2002). De cunho holista, essa forma de construção do conhecimento, contudo, no âmbito das ciências sociais, apenas recentemente adquiriu expressão, como forma de explicar e possibilitar a compreensão dos fenômenos e dos processos que vêm caracterizando as transformações acima aludidas. Essa perspectiva consegue avançar no sentido da compreensão dos processos em curso, sobretudo por permitir perceber o homem, sujeito, indivíduo, como também as organizações sociais, como sistemas conectados a outros sistemas, formando uma rede interligada. Os resultados da aplicação dessa abordagem, contudo, têm tendido, por um lado, a uma espécie de funcionalismo estrutural (Domingues, 1999, p. 34) e, por outro, suas conseqüências, em termos práticos, ainda são modestas, mas, de acordo com Santos (2001, p. 90), prenhes do estabelecimento de uma nova visão do mundo não dualista.

As outras correntes, por seu turno, parecem se encontrar envoltas pelo sonho iluminista do homem ideal, o indivíduo racional, que ora age maximizando suas utilidades, esperando que a ação egoísta 
promova o bem-comum; ora age, também no sentido do bem-comum, buscando pôr a história no seu eixo, mas, ambos, com uma percepção utilitarista do que não é humano. Nesse exato ponto, a maior das transformações hoje vivenciadas pelo homem neste último meio século, aquelas provocadas pela natureza, como resposta às interferências antrópicas nos meios físico e biótico, pegou como que de roldão aquelas duas primeiras formas de se perceber a realidade. Colocou assim em xeque a idéia de progresso a elas inerente e, em conseqüência, suas respectivas posturas ideológicas e seus desdobramentos em termos da ação política e das instituições criadas no seu bojo. Com relação a esse ponto, assim Santos (2001, p. 27) se refere:

Neste domínio, a teoria crítica moderna partilhou com a Sociologia convencional dois pontos importantes. Por um lado, a concepção do agente histórico corresponde por inteiro à dualidade entre estrutura e ação que subjaz a toda a Sociologia. Por outro lado, ambas as tradições sociológicas tiveram a mesma concepção das relações entre natureza e sociedade e ambas viram na industrialização a parteira do desenvolvimento. Não admira, pois, que, neste domínio, a crise da teoria crítica moderna se confunda em boa parte com a crise da Sociologia em geral.

Ao mesmo tempo que assistimos às mudanças no clima - o aumento da temperatura média do planeta, o aprofundamento dos problemas derivados dos diversos tipos de poluição, alterações na biodiversidade e suas consequiências para a produção agrícola e para o equilíbrio ecológico entre as espécies -, assistimos também ao aumento do fosso que separa os mais ricos dos mais pobres, com o crescimento destes últimos evidenciando uma brutal concentração da riqueza existente nas mãos de poucos. Nesse contexto, a carência em termos de alimentos, saúde, educação, trabalho, segurança se reproduz em meio ao aumento generalizado da violência, sem que existam mecanismos públicos ou coletivos eficazes sequer para estancar, quiçá para reverter, esse processo de exclusão social e degradação ambiental, que caminha a passos largos. ${ }^{2}$

Dentro do quadro colocado acima, nos parece que a questão singular, de cunho teórico e prático, que se coloca para as Ciências Sociais, hoje, é que a construção dos mecanismos dos quais se falou 
pressupõe a compreensão dos processos em curso, para que neles se possa interferir. O problema maior, contudo, aí embutido, a nosso ver, é que as formas disponíveis para se compreender os processos em curso, oriundas das posturas metodológicas às quais acima se referiu, não dão mais conta dessa tarefa e nossa capacidade de chegar um pouco mais perto da realidade e avançar na compreensão de sua lógica e dinâmica está seriamente comprometida.

Mais especificamente, existem processos sociais em curso e, até recentemente, dois olhares sobre eles, cuja capacidade de compreensão perdeu muito de sua significância a partir das mudanças que daqueles processos irromperam nos últimos cinqüenta anos. Antes, era possível olhar a história como que esticando uma linha que perpassava um todo que se apresentava mais ou menos coerente. Existiam conceitos e categorias que permitiam construir estratégias políticas de transformação social. O que ocorreu, contudo, foi que essa linha se partiu em vários pontos, ao mesmo tempo que ela deixou de perpassar os processos mais fundamentais. Os conceitos de que se fala são os de progresso, desenvolvimento, classes sociais, luta de classes, entre outros, os quais subsidiavam estratégias, seja no sentido da superação do subdesenvolvimento - a promoção da industrialização -, seja no sentido de estratégias de ruptura política - o socialismo e que davam curso aos processos mais fundamentais de consolidação do capitalismo enquanto sistema social. Nas palavras de Santos (2001, p. 25),

Esses conceitos e as configurações teóricas em que eles se integram são ainda hoje parte integrante do trabalho dos sociólogos e cientistas sociais e, à luz disso, é defensável pensar-se que afinal continua hoje a ser tão fácil ou tão possível produzir teoria social como antes. Julgo, contudo, que assim não é. (...) muitos desses conceitos deixaram de ter a centralidade de que gozavam antes ou foram internamente tão reelaborados e matizados que perderam muito da sua força crítica.

Essa dificuldade, inerente aos arcabouços teóricos que informam as ciências sociais, já havia sido percebida por Norbert Elias desde antes da Segunda Guerra Mundial. Ele dizia, já se valendo do conceito de campo de disputa, que se tornou posteriormente famoso 
a partir da utilização que dele fez Pierre Bourdieu (1989), que era possível pensar o objeto de estudo das ciências sociais apenas de dois pontos de vista extremados, com base no instrumental teórico que havia sido desenvolvido até aquele momento. Ou se percebia(e) a sociedade enquanto estrutura, dentro da qual o indivíduo, o sujeito, sua consciência e sua forma são por ela definidos; ou se percebia(e) o todo social como algo difuso e a princípio não apreensível, senão pela ação deliberada e distinta de indivíduos racionais. Nesse último caso, a sociedade não era senão um todo fundado nessas ações racionalmente constituídas, enquanto que, no primeiro caso, $o$ indivíduo não desempenhava papel algum (Elias, 1994, p. 14). Na perspectiva desse autor, tal dicotomia, digamos assim, é extensível também aos estudos inerentes à psicologia. Em outro trabalho, discutindo as contribuições de Freud acerca das relações entre as estruturas da personalidade e os grupos sociais, Elias (2000, p. 42) afirma que por mais que ele tenha contribuído para a compreensão dos laços que unem as pessoas, seu conceito do homem continuou a ser, basicamente, o do indivíduo isolado.

Boaventura, por seu turno, como alternativa à compreensão das estruturas sociais inerentes às construções teóricas das quais se falou acima, propõe perceber a realidade a partir de seis espaços estruturais autônomos e ao mesmo tempo interligados entre si. A seguir, nos deteremos um pouco mais nessa contribuição específica do autor para, em seguida, fazermos uma pequena incursão na sociologia de Norbert Elias e, então, propor a inclusão, no Mapa da EstruturaAção, dos espaços do sujeito e grupal.

\section{O mapa da estrutura-ação}

A contribuição maior do autor, a nosso ver, está em, a partir de uma crítica da epistemologia moderna centrada na ciência moderna, no Estado liberal e no direito estatal, conseguir avançar na construção de um quadro conceitual que permite pensar, simultaneamente, as formas de regulação da sociedade contemporânea com as possibilidades de emancipação social nelas contidas. 
Seu argumento principal pode ser sintetizado da seguinte forma: o processo de construção das formas de conhecimento, poder e direito inerentes à vida social, no seu conjunto, foi ocultado na vivência dos processos de regulação social, pela vulgarização da prevalência de apenas uma forma de conhecimento - o conhecimento científico; de apenas uma forma de direito - o direito estatal; e de apenas uma forma de exercício do poder - o poder estatal. Posto isto, a reconstrução teórica dos mecanismos de regulação e emancipação social exige o reconhecimento da perda do monopólio dessas três instituições em relação a outras formas de conhecimento, direito e poder, o que não significa, contudo, a perda de suas centralidades.

Surgem, então, seguindo a construção de tal argumento, as seguintes questões: que formas de conhecimento, direito e poder são essas? Como elas estão articuladas com o conjunto quase infinito de relações sociais que as viabiliza? E como elas se articulam e interagem? No sentido de procurar responder tais questões, Boaventura, partindo da idéia de que os espaços são socialmente construídos, divide a realidade social em seis espaços estruturais: o doméstico, da produção, do mercado, da comunidade, da cidadania e o mundial. Desloca, assim, para o centro do entendimento dos processos sociais as questões relativas ao poder e seu exercício. Partindo da análise marxista e da teoria da dependência acerca das relações entre países centrais e periféricos, o autor passa a perceber o poder essencialmente como uma troca desigual. Essa troca desigual ocorre sobretudo dentro dos próprios campos (isto é, dentro dos próprios espaços estruturais) e cujo exercício permite a acumulação de uma espécie de "capital" (em ambos os casos, a referência aqui é Bourdieu, 1989), que se reproduz de uma maneira contraditória: estabelecendo limites e ampliando horizontes, fixando fronteiras e abrindo caminhos.

Desde que relativizou, a partir de Foucault e das teorias feministas, a prática de poder estatal, de modo que a própria sociedade produz o poder que nela circula - um poder disciplinar exercido horizontalmente pelos próprios sujeitos, a começar pelo corpo humano, a questão de como pensar estruturalmente o exercício do 
poder a partir de um conjunto de relações sociais incomensuráveis fica em aberto. A proposta do autor é pensar tal exercício a partir de "constelações" de relações de poder que tendem a se reforçar ou a se neutralizar entre si. No caso de não se neutralizarem, novos limites e horizontes são estabelecidos.

O exercício do poder em cada um dos espaços estruturais encontra-se baseado numa determinada forma de conhecimento e de direito, unidades de prática social e instituições que lhes são características e predominantes, as quais, por sua vez, se orientam em função de uma dinâmica de desenvolvimento específica. Isso está apresentado no Mapa da Estrutura-Ação a seguir aqui reproduzido. Assim, por exemplo, no espaço doméstico, a forma de poder predominante é o patriarcado, forma essa que se legitima através do direito doméstico e da cultura familiar, fundadas no aceite das diferenças sexual e geracional e em instituições como o casamento, a família e o parentesco. Sua dinâmica de desenvolvimento caminha no sentido da maximização da afetividade entre os membros que partilham da coexistência nesse espaço estrutural.

As diferenças sexual e geracional são as unidades de prática social prevalecentes no espaço doméstico, pois que definem que os homens, em princípio, mais fortes em relação às mulheres e mais capacitados em relação aos mais jovens, devem ter sua vontade respeitada, para o bem de todos. Isso é constitutivo da cultura familiar, se mantendo a partir de instituições como o casamento e a família e se reproduzindo através de relações que buscam maximizar a afetividade entre seus membros. No campo doméstico, portanto, o signo da paternidade garante ao pai a hegemonia sobre os grupos dominados - esposas, filhos e agregados, assentada na propriedade de um certo tipo de capital que lhe é específico - a força física e a capacidade de prover. A disputa diária pelo poder nesse campo, regulada pelo direito doméstico e pela cultura familiar, forma um habitus que é peculiar à ação de seus membros, dominantes e dominados. Esse habitus acaba por reproduzir as instituições que são inerentes a esse espaço - o casamento, a família e o parentesco, tendo como referência a maximização da afetividade. Desse modo, menos 
afetividade tende à desagregação do grupo familiar, comprometendo a sobrevivência de todos, e vice-versa.

\section{Mapa de estrutura-ação das sociedades capitalistas no sistema mundial}

\begin{tabular}{|c|c|c|c|c|c|c|}
\hline $\begin{array}{l}\text { Dimensões/ } \\
\text { Espaços } \\
\text { Estruturais }\end{array}$ & $\begin{array}{c}\text { Unidade } \\
\text { de Prática } \\
\text { Social }\end{array}$ & Instituições & \begin{tabular}{|c|} 
Dinâmica \\
de \\
Desenvolvi- \\
mento
\end{tabular} & $\begin{array}{l}\text { Forma } \\
\text { de } \\
\text { Poder }\end{array}$ & $\begin{array}{l}\text { Forma } \\
\text { de } \\
\text { Direito }\end{array}$ & $\begin{array}{c}\text { Forma } \\
\text { Epistemo- } \\
\text { Lógica }\end{array}$ \\
\hline $\begin{array}{c}\text { Espaço } \\
\text { Doméstico }\end{array}$ & $\begin{array}{l}\text { Diferença } \\
\text { sexual e } \\
\text { geracional }\end{array}$ & \begin{tabular}{|c|} 
Casamento, \\
família e \\
parentesco \\
\end{tabular} & \begin{tabular}{|c|} 
Maximiza- \\
Ção da \\
afetividade
\end{tabular} & Patriarcado & $\begin{array}{c}\text { Direito } \\
\text { doméstico }\end{array}$ & $\begin{array}{c}\text { Familismo } \\
\text { Cultura } \\
\text { Familiar }\end{array}$ \\
\hline $\begin{array}{l}\text { Espaço da } \\
\text { Produção }\end{array}$ & $\begin{array}{c}\text { Classe e } \\
\text { natureza, } \\
\text { enquanto } \\
\text { natureza } \\
\text { capitalista }\end{array}$ & $\begin{array}{l}\text { Fábrica e } \\
\text { empresa }\end{array}$ & \begin{tabular}{|c|} 
Maximiza- \\
Cão do lucro \\
e da \\
degradação \\
da natureza
\end{tabular} & $\begin{array}{c}\text { Exploração } \\
\text { e natureza } \\
\text { capitalista }\end{array}$ & $\begin{array}{l}\text { Direito } \\
\text { da } \\
\text { produção }\end{array}$ & $\begin{array}{l}\text { Produtivis- } \\
\text { mo, tecno- } \\
\text { logismo } \\
\text { formação } \\
\text { profissional } \\
\text { e cultura } \\
\text { empresarial }\end{array}$ \\
\hline $\begin{array}{l}\text { Espaço de } \\
\text { Mercado }\end{array}$ & $\begin{array}{l}\text { Cliente- } \\
\text { consumidor }\end{array}$ & Mercado & \begin{tabular}{|c|} 
Maximiza- \\
ção da \\
utilidade e \\
da mercado- \\
rização de \\
necessida- \\
des
\end{tabular} & $\begin{array}{l}\text { Fetichismo } \\
\text { das } \\
\text { mercadorias }\end{array}$ & $\begin{array}{l}\text { Direito } \\
\text { da } \\
\text { troca }\end{array}$ & $\begin{array}{l}\text { Consumis- } \\
\text { mo e } \\
\text { cultura de } \\
\text { massa }\end{array}$ \\
\hline $\begin{array}{l}\text { Espaço da } \\
\text { Comuni- } \\
\text { dade }\end{array}$ & $\begin{array}{l}\text { Etniciade, } \\
\text { raça, nação, } \\
\text { povo, } \\
\text { religião }\end{array}$ & \begin{tabular}{|c|} 
Comuni- \\
dade \\
vizinhança, \\
região, org. \\
populares \\
de base, \\
Igrejas. \\
\end{tabular} & $\begin{array}{l}\text { Maximiza- } \\
\text { ção da } \\
\text { identidade }\end{array}$ & $\begin{array}{c}\text { Difencia- } \\
\text { ção desigual }\end{array}$ & $\begin{array}{c}\text { Direito da } \\
\text { comunidade }\end{array}$ & $\begin{array}{l}\text { Conheci- } \\
\text { mento local } \\
\text { cultura da } \\
\text { comunidade } \\
\text { e tradição }\end{array}$ \\
\hline $\begin{array}{l}\text { Espaço da } \\
\text { Cidadania }\end{array}$ & Cidadania & Estado & $\begin{array}{l}\text { Maximiza- } \\
\text { ção da } \\
\text { lealdade }\end{array}$ & Dominação & $\begin{array}{c}\text { Direito } \\
\text { territorial } \\
\text { (Estatal) }\end{array}$ & \begin{tabular}{|} 
Naciona- \\
lismo \\
educacional \\
e cultural, \\
cultura \\
cívica
\end{tabular} \\
\hline $\begin{array}{c}\text { Espaço } \\
\text { Mundial }\end{array}$ & $\begin{array}{c}\text { Estado } \\
\text { Nação }\end{array}$ & \begin{tabular}{|c|} 
Sistema \\
inter- \\
estatal, \\
organismos \\
e assoc. \\
intern., \\
tratados \\
internacio- \\
nais \\
\end{tabular} & $\begin{array}{l}\text { Maximi- } \\
\text { zação da } \\
\text { eficácia }\end{array}$ & $\begin{array}{l}\text { Troca } \\
\text { desigual }\end{array}$ & $\begin{array}{l}\text { Direito } \\
\text { sistêmico }\end{array}$ & $\begin{array}{l}\text { Ciência, } \\
\text { progresso } \\
\text { Universa } \\
\text { lístico, } \\
\text { cultura } \\
\text { global }\end{array}$ \\
\hline
\end{tabular}

Fonte: Santos (2001, p. 273). 
O exercício do poder nesse espaço, além disso, subjaz ao exercício do poder em todos os outros espaços. Isto é, a sociedade como um todo é patriarcal, como também é capitalista, nacional, conforma uma comunidade, um mercado e um espaço de produção e essa forma de colocar a questão permite que o autor fale de constelações de relações de poder, de direito e de conhecimento que caminham no sentido de reproduzir toda a estrutura social, sob a égide das relações de poder, de direito e de conhecimento prevalecentes nos espaços da cidadania e mundial. Isto porque, em primeiro lugar, é no espaço da cidadania que encontramos o Estado liberal, instituição organizadora das sociedades nos âmbitos local, regional e global. Sua organização se dá predominantemente pela imposição do direito territorial-estatal e pela credibilidade que o conhecimento proveniente da Ciência Moderna - forma epistemológica do espaço mundial - assumiu ao longo da modernidade, ofuscando ou legitimando as outras formas de direito e de conhecimento prevalecentes nos demais espaços estruturais.

Além disso, é nesses espaços que se encontram instalados os poderes inerentes ao capitalismo financeiro global. Mais especificamente, é no espaço mundial que se pode perceber mais claramente a ação das grandes corporações capitalistas no sentido de estenderem seus interesses em torno do processo de valorização do capital. Essas colocações são fruto da aceitação parcial, por parte de Boaventura, do que vem se convencionando chamar de A Teoria do Sistema Mundial. Isto é, o espaço mundial consiste na representação, no plano dos espaços estruturais, do sistema mundial, objeto de estudo da "Teoria do Sistema Mundial", a qual propõe uma releitura do processo de constituição do capitalismo, principalmente a partir das contribuições de Fernand de Braudel e Karl Polanyi. Não é nosso interesse aqui passar em revista tais contribuições. Apenas dizer que elas se valem das considerações de Marx em torno do processo de valorização do capital e de Max Weber, em torno da organização do sistema mundial. E, a partir dessas considerações, Boaventura organiza o que para ele passou a ser o espaço mundial (cf. Fiori, 1999). ${ }^{3}$

Esse espaço se coloca como sendo a matriz organizadora das condições e das hierarquias mundiais sobre os outros espaços e se caracteriza por estar estreitamente relacionado com os espaços da 
produção e do mercado. Constitui-se assim uma reciprocidade e simbiose entre as dinâmicas de desenvolvimento desses espaços, cujo resultado é o aprofundamento da divisão global do trabalho e o estabelecimento de hierarquias entre países, sociedades, regiões e povos, perpetuadas pelas trocas desiguais e pela prevalência no espaço mundial da Ciência Moderna, como forma privilegiada de conhecimento. Pode-se então dizer que o espaço mundial interfere mais nos espaços da produção, do mercado e da cidadania do que nos espaços da comunidade e doméstico e, como veremos a seguir, nos espaços grupal e do sujeito.

Dessa forma, o Mapa da Estrutura-Ação se posta como uma alternativa à teoria do sistema mundial, que se baseia apenas em uma única macro-estrutura: a divisão mundial do trabalho: $o$ desenvolvimento das sociedades capitalistas, como um todo, estão alicerçados nas constelações formadas pelos espaços estruturais, e não em qualquer dos espaços estruturais tomados individualmente (Santos, 2001, p. 314).

Além disso, fazendo referência a Wallerstein, ressalta a utopia que ressurge em face das possibilidades e alternativas às crises sociais locais, mediante transformações profundas que possam vir a ocorrer no âmbito das relações de poder prevalecentes nos espaços doméstico e da comunidade. Aqui fica clara a principal diferença da dinâmica entre regulação e emancipação no contexto da transição paradigmática. É que as possibilidades de transformação da ordem social, ou, melhor dizendo, de emancipação social em relação ao jugo do poder prevalecente no espaço mundial, nesse contexto, encontram-se mais claramente dadas do que nunca. A crise de regulação no âmbito mundial, quando não coloca alternativas para o processo de reprodução social nos níveis local e regional, senão aquela condizente com o aprofundamento da pauperização da maior parte das populações, acaba por enfraquecer suas instituições predominantes - o Estado liberal, o direito estatal-territorial e o conhecimento científico - em favor de outras formas de organização territorial do espaço, de direito e de conhecimento. Abre-se então a possibilidade para que, principalmente no âmbito dos domicílios e das comunidades, 
com conseqüências sobre os espaços da cidadania, do mercado e da produção, se privilegie a solidariedade e a participação em detrimento da maximização do lucro e a maximização das utilidades; o homem em detrimento do bem material; a democracia em detrimento do autoritarismo; a igualdade na diversidade em detrimento da diferenciação desigual; a colaboração em detrimento da exploração; o desenvolvimento sustentável em detrimento da escravização da natureza; a satisfação de necessidades em detrimento do fetichismo das mercadorias.

Cabe, por fim, aqui ressaltar a importância da crítica ao paradigma dominante contida na contribuição de Boaventura. Essa crítica acaba por legitimar as formas de organização políticoterritorial, de direito e de conhecimento que surgem - ou ressurgem dessa prática social criativa, ao mesmo tempo que permite a troca de conhecimentos entre as mais variadas experiências no sentido acima apontado e permite também a melhor compreensão dos processos em curso. Preenche, assim, pelo menos parte da lacuna deixada pela crise paradigmática, o que, por sua vez, possibilita desdobramentos no que respeita à construção de alternativas políticas de intervenção sobre a realidade.

\section{Uma introdução à Sociologia de Norbert Elias $^{4}$}

A crítica à tendência de olhar o funcionamento das sociedades, seja a partir do indivíduo isolado, seja a partir de uma estrutura préconcebida, parece ser o ponto de partida de Elias para construir toda a sua contribuição à Sociologia. Ele procurava entender como o todo social se constitui e se desenvolve, levando em consideração o fato de que o indivíduo, bem como sua estrutura psicológica e sua subjetividade e os grupos e a consciência coletiva que eles formam mais do que fazem parte. Ele, o indivíduo (o eu), da mesma forma que os grupos (o nós) é e são agentes, sujeitos de um processo dialético, cuja compreensão só pode acontecer a partir, ao mesmo tempo, de suas respectivas presenças e ações, sua interatividade com outras pessoas e dos grupos que elas formam com outros grupos, bem como 
a partir do ambiente simbólico que cada geração encontra ao iniciar sua vivência.

Para o autor, as relações que pressupõem essa interatividade complexa entre pessoas, entre grupos e entre gerações são essencialmente relações de poder. Elas se expressam na compreensão que esses atores têm de si mesmos e dos outros, no conhecimento e nos costumes, bem como na forma de repassá-los de geração para geração, os quais, no conjunto, formam um tipo de habitus particular de cada grupo e cada geração. Sua compreensão dos processos constitutivos e de desenvolvimento das sociedades envolve, portanto, uma dimensão que é estrutural e uma dimensão que leva em conta a subjetividade e o cotidiano das pessoas e dos grupos, fugindo também do determinismo estrutural e do individualismo metodológico. Isso permite ver o indivíduo e os grupos que eles formam como sujeitos e atores da construção do ambiente no qual suas próprias vidas transcorrem, ambiente esse que, por sua vez, seja pelas relações de poder que o configuram, seja pelos limites cognitivos e subjetivos que o conformam, delimita, ou melhor, cria fronteiras para o potencial de desenvolvimento dos atores, vistos na forma de indivíduos ou na forma de grupos.

Tomando como objeto de estudo da Sociologia as redes de inter-relações, as interdependências, as configurações e os processos formados por homens interdependentes, o autor procura responder a questões do tipo: como e por que os indivíduos estão ligados entre si, constituindo configurações dinâmicas específicas? Como ocorre o desenvolvimento dessas configurações e, em conseqüência, os processos de evolução social? Seu ponto de partida é a constatação de que a história transcorre em três tempos distintos: o tempo biológico, onde ocorrem as mudanças nas estruturas biológicas; o tempo social, das estruturas das formações sociais; e o tempo individual, relativo à vida dos indivíduos. Dadas as especificidades do ser humano, o autor diferencia o primeiro dos dois últimos e afirma que "As estruturas da psique humana, as estruturas da sociedade humana e as estruturas da história humana são indissociavelmente complementares, só podendo ser estudadas em conjunto" (Elias, 1994, p. 38). 
As especificidades de que se falou estão sintetizadas no fato de que, para Elias, os indivíduos só podem ser compreendidos enquanto ligados entre si - só é possível $o e u$, quando se pressupõe $o$ nós, em relações de interdependências recíprocas, que implicam ao mesmo tempo solidariedade e coerção, tanto no sentido dos dominantes em relação aos dominados e vice-versa. A idéia de liberdade, então, só é possível de ser pensada em termos relativos, isto é, dada a cadeia obrigatória de interdependências que, antes de tudo, se constituem de relações intersubjetivas historicamente variáveis, dependentes das exigências próprias de cada configuração. Nesse contexto, os processos de transformação e evolução social pressupõem a existência de um equilíbrio móvel de tensões que se instaura, se perpetua ou se rompe em função: a) das mudanças nas relações de poder e força dos grupos envolvidos; e b) do advento de um novo grupo, que recusa sua exclusão no processo de disputa pelas oportunidades de poder. Essas oportunidades podem ser sintetizadas nas possibilidades de controle sobre os mecanismos da violência e uso da força; no controle sobre os fluxos de riqueza; e no controle da produção de signos e representações da realidade, inerentes a cada configuração.

Além disso, cada configuração possui um habitus que lhe é inerente e que se constitui num instrumento de dominação. Para o autor, a civilização enquanto configuração tem como habitus que lhe é próprio a autocoerção psíquica, derivada de um mecanismo de condicionamento social, graças ao qual cada indivíduo é educado no sentido de um rigoroso autocontrole. Esse mecanismo é em parte automático e implica o autocontrole sobre pulsões e emoções e permite a passagem da coerção social para a autocoerção. Ele também pressupõe, do ponto de vista dos indivíduos, algumas propriedades psicológicas específicas: a arte da observação de si e dos outros; a censura dos sentimentos; o domínio das paixões; e a incorporação de disciplinas. Do ponto de vista dos grupos que esses indivíduos conformam, o mecanismo de condicionamento social pressupõe a representação da posição social pela forma, pela aparência e pela estética, de modo que a hierarquia de habitus específicos é também um modelo de diferenciação social. Este modelo se encontra na base 
dos processos de competição levada a cabo pelos grupos sociais. A identidade individual, então, passa a ser dada pela contradição entre a representação que as pessoas se esforçam em construir de si mesmas versus o crédito concedido pelos outros em relação à sua pessoa. Assim, a disputa pelos signos do prestígio dá sentido à luta por vantagens e poder social.

Finalmente, essa breve incursão na obra de Elias não ficaria satisfatória se não colocássemos em evidência que a noção de indivíduos interdependentes difere radicalmente daquilo que o autor chama de homo clausus, isto é, o indivíduo como centro de uma estrutura que se ergue em seu entorno e que vai desde a família até o Estado. O indivíduo de que nos fala o autor é aquele que faz parte de um todo social cuja representação é aberta no sentido da multiplicidade de suas possibilidades, dadas as suas qualidades intrínsecas, as múltiplas configurações da qual faz parte e o equilíbrio de forças mais ou menos instável a cada uma delas inerente (Elias, 1991).

O autor, assim, abre caminhos em relação à transição paradigmática, mesmo antes dela ter sido formulada. Posto isto, a seguir voltaremos a dialogar com Boaventura, propondo a inclusão, em seu Mapa da Estrutura-Ação, dos espaços do sujeito e grupal.

\section{O espaço do sujeito}

A construção teórica do espaço do sujeito exige uma crítica do indivíduo racional que nasceu com a modernidade, um indivíduo ideal concebido no âmbito da revolução iluminista que muito longe está dos sujeitos concretos. Essa crítica, contudo, deve admitir que a modernidade produziu o sujeito-indivíduo como unidade de prática social, no sentido de que ele estabelece uma relação com ele mesmo. Se, por um lado, ao longo da modernidade essa relação foi constituída no sentido da internalização do processo de regulação de determinada ordem, contendo impulsos, modelando condutas e promovendo a autoobservação, o autodomínio e a observação dos outros, em direção ao 
auto-interesse, separando o interno do externo, por outro, contribuiu para a própria possibilidade da intensificação da experiência individualizada, de modo que o indivíduo se coloca como o modo hegemônico de organização da subjetividade na modernidade (Mancebo, 2002, p. 102, 100).

Dois aspectos devem aqui ser ressaltados: o primeiro está relacionado às formas de regulação que foram capazes de fazer com que os indivíduos passassem a conter seus impulsos menos nobres, suas paixões avassaladoras, através da válvula reguladora do autointeresse. ${ }^{5} \mathrm{O}$ segundo encontra-se relacionado com a explicitação dos limites desse processo regulador no contexto da transição paradigmática.

Nossa proposta, aqui apresentada é que, no que respeita ao processo regulador acima referido, a diferenciação externo / interno produziu o desenvolvimento de uma forma de poder que se exerce internamente sobre os indivíduos, e pelos próprios indivíduos, a qual designamos de culpa: o sentimento de culpa advém do fato de que, ao deixar vazar impulsos menos nobres em detrimento daqueles condizentes com o auto-interesse, ele, o sujeito, deixaria de estar contribuindo para a maximização do bem-estar no âmbito da família, da comunidade, e do Estado. Exerce, então, sobre ele mesmo uma forma de direito específica - a auto-censura, com base numa forma epistemológica também específica: o auto-conhecimento.

Como a auto-imagem e a auto-estima só possuem sentido se se considera o indivíduo inserido em determinado contexto social, que possui os outros como referência, da forma como asseverou Elias, sua maximização, isto é, a maximização da auto-imagem e da autoestima constitui-se na dinâmica de desenvolvimento sobre a qual o espaço do sujeito se estrutura.

Essa estruturação, além disso, parece estar de acordo com os limites e critérios desenvolvidos por Boaventura na construção de seu Mapa. Isto é, no que respeita às formas de poder, "todas elas são trocas desiguais [de modo que] formas diferentes de troca desigual dão origem a formas diferentes de poder" (Santos, 2001, p. 284). 
Nesse caso, a troca desigual acontece entre a busca dos benefícios materiais fruto da ação auto-interessada e a expressão fidedigna dos seus impulsos tidos, nos termos de Hirschman, na ordem social prevalecente ao longo da modernidade, como avassaladores. Essa troca desigual acaba por se constituir num dos aspectos da crítica à modernidade, que encontra-se assentado na revalidação do indivíduo como ele é: o respeito aos seus verdadeiros sentimentos e impulsos, longe do indivíduo racional e homogêneo da ordem capitalista.

\section{Mapa da Estrutura-Ação: o espaço do sujeito}

\begin{tabular}{|c|c|c|c|c|c|c|}
\hline $\begin{array}{c}\text { Dimensões/ } \\
\text { Espaços } \\
\text { Estruturais }\end{array}$ & $\begin{array}{c}\text { Unidade de } \\
\text { Prática } \\
\text { Social }\end{array}$ & Instituições & $\begin{array}{c}\text { Dinâmica de } \\
\text { Desenvolvi- } \\
\text { mento }\end{array}$ & $\begin{array}{c}\text { Forma } \\
\text { de } \\
\text { Poder }\end{array}$ & $\begin{array}{c}\text { Forma } \\
\text { de } \\
\text { Direito }\end{array}$ & $\begin{array}{c}\text { Forma } \\
\text { Epistemológica }\end{array}$ \\
\hline $\begin{array}{c}\text { Espaço do } \\
\text { Sujeito }\end{array}$ & $\begin{array}{c}\text { Relação do } \\
\text { indivíduo } \\
\text { com ele } \\
\text { mesmo }\end{array}$ & Indivíduo & $\begin{array}{c}\text { Maximização } \\
\text { da auto- } \\
\text { imagem e } \\
\text { estima }\end{array}$ & Culpa & $\begin{array}{c}\text { Auto- } \\
\text { censura }\end{array}$ & $\begin{array}{c}\text { Auto- } \\
\text { conhecimento }\end{array}$ \\
\hline
\end{tabular}

A concepção de direito adotada por Boaventura, da mesma forma, é capaz de encampar a forma de direito proposta para regular, juntamente com a sua forma epistemológica e de poder específicas, o espaço do sujeito. Isto é, para o autor, o direito é um corpo de procedimentos regularizados e de padrões normativos considerados justificáveis num dado grupo social, que contribui para a criação e prevenção de litígios e para a sua resolução através de um discurso argumentativo, articulados com a ameaça de força (Santos, 2001, p. 290). A definição do que é bom e do que é ruim, do que pode e do que não pode é algo convencionado nos outros espaços estruturais, que podem então ser considerados como padrões normativos internalizados pelo sujeito como critério para avaliar sua conduta, base para o exercício da auto-censura, forma específica de direito exercida no espaço do sujeito. Essa forma de direito, ao mesmo tempo, é passível de ser objeto de discurso, o qual o próprio sujeito pode empreender e, na verdade, empreende, para normatizar sua conduta e estabelecer punições, autopunições que, no limite, podem levá-lo a infringir sobre si mesmo a sua auto-anulação ou autodestruição, por meio da autoviolência. 
Esse processo de argumentação e contra-argumentação que tem o espaço do sujeito como espaço privilegiado, por sua vez, se fundamenta no auto-conhecimento, forma epistemológica prevalecente nesse espaço. Auto-conhecimento, assim, é uma forma de saber que se desenvolve no interior dos próprios indivíduos, em torno da relação entre o externo e o interno que, como sujeitos sociais, estabelecem desde o nascimento. Essa forma de conhecimento específica, também da mesma forma que as formas epistemológicas sobretudo dos espaços doméstico e da comunidade, foi ofuscada pelo conhecimento proveniente da Ciência Moderna. A psicanálise aqui exerceu papel fundamental nesse processo de ofuscação, impedindo que o sujeito pudesse vir a se conhecer/reconhecer a partir de outros critérios que não os desenvolvidos por Freud, fundados em outros paradigmas que não os da cientificidade moderna.

Assim, de acordo com Elias (1994), da mesma forma que as ciências sociais, que concebem a relação entre indivíduo e sociedade ora a partir apenas da existência concreta dos primeiros, sem nenhuma significância para a segunda, e vice-versa, na psicologia

(...) encontram-se, de um lado, ramos de pesquisa que tratam o indivíduo singular como algo que pode ser completamente isolado e que buscam elucidar as estruturas de suas funções psicológicas independentemente de suas relações com as demais pessoas. Por outro lado, encontram-se as correntes, na psicologia social ou de massa, que não conferem nenhum lugar apropriado às funções psicológicas do indivíduo singular. Às vezes, os membros deste último campo, mais ou menos como seus equivalentes nas ciências sociais ou históricas, atribuem a formações sociais inteiras, ou a uma massa de pessoas, uma alma própria que transcende as almas individuais, uma anima collectiva ou mentalidade grupal. E quando não chegam a ir tão longe, é comum se contentarem em tratar os fenômenos sócio-psicológicos como a soma - ou o que dá na mesma - a média das manifestações psicológicas de muitos indivíduos. (Elias, 1994, p. 15; grifos no original)

A dicotomia entre sociedade e indivíduo fica assim em evidência e, de acordo com esse autor, não é possível compreender a sociedade, sua história e o curso que segue sem que se compreenda de que modo um grande número de indivíduos compõem entre si 
algo maior e diferente de uma coleção de indivíduos isolados (Elias, 1994, p. 16). Valendo-se ainda da metáfora que o autor utiliza, essas partes separadas não possuem sentido apenas quando encontram-se juntas, formando algo maior do que elas próprias: seremos também nós, como seres humanos individuais, não mais que um meio que vive e ama, luta e morre, em prol do todo social? (Elias, 1994, p. 16).

$\mathrm{O}$ que se pretende demonstrar aqui, em primeiro lugar, é a presença dessa forma de subjetividade específica à modernidade e ao capitalismo. Em segundo lugar, contudo, essa subjetividade, como nos é apresentada, aparece mais como um resultado, uma consequiência daqueles processos históricos, do que também como uma causa compartilhada desses processos, a partir de indivíduos interdependentes, nos termos de Elias.

É nesse último sentido, ao mesmo tempo como causa e como consequiência, que também Giddens (1997) argumenta para poder explicar as grandes transformações dos últimos trinta anos. Aponta então o surgimento do sujeito da psicanálise como uma das causas privilegiadas, que levaram ao colapso da modernidade e ao advento de uma sociedade pós-tradicional. Nesse contexto, a auto-reflexão promoveu a desmistificação das tradições - valores, crenças prevalecentes nas comunidades tradicionais, ao mesmo tempo que o sujeito do conhecimento que surgiu com o paradigma da ciência moderna eliminou o caráter místico do saber, colocando a todos a possibilidade de acessar o conhecimento. Assim, a evidência da desconstrução das sociedades tradicionais estaria no fato de que quando, nos contextos pós-tradicionais, não temos outra escolha senão decidir como ser e como agir (Giddens, 1997, p. 94). ${ }^{6}$

Não é, contudo, apenas o caráter ativo da subjetividade sobre a realidade, aqui representado pela capacidade de escolher, que no momento nos interessa apontar, mas também o fato de que o exercício soberano dessa subjetividade implica reconhecer a existência de um espaço de diálogo - diálogo que o sujeito mantém com ele mesmo, o que, nos parece, já estava presente em Elias. O exercício desse diálogo implica, ao mesmo tempo, o reconhecimento de que, com o advento da modernidade, ou do processo civilizador, se estabelece, entre tantas 
outras, uma relação entre o indivíduo e ele mesmo. A despeito do fato de ser isto também o que a psicanálise ou as terapias de um modo geral estimulam, isto é, a busca do auto-conhecimento no sentido de fazer com que o sujeito, a partir da relação que estabelece consigo mesmo, caminhe no sentido da maximização da auto-imagem e da auto-estima, o conteúdo dessa relação foi negligenciado em termos da compreensão dos processos em curso, vale dizer dos processos de construção do espaço social.

Ao mesmo tempo, a relação que o indivíduo estabelece consigo mesmo, num contexto de crise paradigmática, implica a possibilidade de se pensar a tensão entre regulação e emancipação a partir também do espaço do sujeito. Isto é, a crise da modernidade leva ao estabelecimento de parâmetros diferenciados nos quais o indivíduo pauta a sua conduta e o estabelecimento de relações: surgem novos veios sobre os quais o certo e o errado podem ser sentidos e pensados, com implicações profundas sobre o novo sujeito que está a nascer. Isto vem alterando as relações entre as gerações, os padrões prevalecentes nos espaços domésticos e a conformação de comunidades, e ainda sobre as relações nos espaços do mercado e da produção, embora nesses dois últimos espaços, os impactos ainda sejam quase imperceptíveis, da mesma forma que nos espaços da cidadania e no espaço mundial.

\section{O espaço grupal}

À medida que a modernidade foi se desenvolvendo, juntamente com os processos de urbanização e industrialização, uma nova forma de sociabilidade se desenvolveu e o argumento aqui que se pretende construir encontra-se baseado no fato de que, da mesma forma que ocorreu com a dissolução das sociedades tradicionais, as relações familiares vão perdendo espaço para um outro tipo de relações que os sujeitos passam a estabelecer com iguais. A questão da identidade aqui é fundamental, conformando grupos sociais os quais não podem nem devem ser concebidos como que inseridos no espaço doméstico, ao mesmo tempo que também não devem servir de síntese para a formulação dos espaços da comunidade. 
Em outras palavras, numa estrutura social qualquer, o conjunto das relações sociais predominantes podem ser percebidas a partir do espaço doméstico e do espaço da sociedade. Contudo, e é isto que se pretende enfatizar, existe um outro conjunto dessas relações, potencialmente já existente, mas que se desenvolveu com a própria modernidade, que não se sintetiza nas relações familiares nem nas comunitárias e que possuem uma dinâmica própria, com relações de poder, de direito e de conhecimento que lhes são características. Falase aqui do espaço grupal e seu desenvolvimento encontra-se, mas não apenas, na própria conformação de grandes centros urbanos, onde predomina e prevalece a impessoalidade e a inexistência de limites para a ação de sujeitos, que não aqueles colocados pelo espaço da cidadania, provenientes do direito estatal-territorial.

Castells (2000, v. 2) nos fala das identidades de resistência e das identidades de projetos, de modo que

(...) a lógica dominante da sociedade em rede lança seus próprios desafios, na forma de identidades de resistência comunais e de identidades de projeto que podem eventualmente surgir desses espaços, $\underline{\text { sob determinadas circunstâncias, e por meio de processos específicos }}$ a cada contexto institucional e cultural. A dinâmica de contradição daí decorrente está no cerne do processo histórico pelo qual uma nova estrutura social e a 'carne e os ossos' de nossas sociedades estão sendo constituídas. (Castells, 1999, p. 423; grifos no original)

$\mathrm{O}$ autor nos fala, sobretudo no que respeita às identidades de projetos, dos movimentos que eclodiram a partir da crítica da modernidade e que as manifestações de 1968 foram capazes de sintetizar. Fala-se aqui dos movimentos feministas, ecológicos, assentados na etnia e nas identidades territoriais que, no contexto de uma sociedade em rede, acabam por alterar as correlações de poder nela prevalecentes.

Contudo, o leitor há de perceber que não se trata aqui desse tipo de identidade e tampouco são esses grupos que se pretende evidenciar. Aqui nos referimos aos grupos que se formam nos ambientes de trabalho, de estudo, de prática de lazer, diretamente ligados ao cotidiano das pessoas. No limite, aspiram se constituir 
enquanto famílias, mas não o são; da mesma forma que pretendem formar comunidades. Observemos, por exemplo, um grupo que se forma dentro de uma sala de aula. São também estudantes, mas não se identificam, senão em momentos específicos com o conjunto de estudantes e suas instituições. Se separam dos demais por algum motivo que não coincide com as identidades de projeto e de resistência, tendendo a criar uma linha divisória entre o pertencimento e o não pertencimento. Estudam juntos, vão às festas juntos, comentam intimidades, fofocam e se fortalecem mutuamente, vivendo experiências comuns - ou comungando das mesmas experiências e/ ou estigmatizando os outros em geral e os outros grupos em particular. ${ }^{7}$ Isso pode também ser pensado para um grupo de usuários de droga no bairro; para o grupo de pessoas que fazem parte de uma agremiação política; para um grupo de jovens que praticam pequenos furtos, ou ainda para um grupo de funcionários de uma agência bancária.

Quando Foucault (2002) adverte para o fato de que o poder que predomina nos contextos sociais é horizontal e não vertical, que ele se estabelece sobretudo entre os iguais, a despeito das relações de poder entre diferentes, torna possível se pensar que, para além das unidades familiares e para aquém das comunidades e dos grupos politicamente organizados, pode-se observar outras construções sociais, fundadas em identificações de cunho mais subjetivo que objetivo e mais relacionadas ao devir da própria vida das pessoas que aos processos históricos e políticos mais gerais. Nesse sentido, afirma o autor:

Existe atualmente um grande desconhecido: quem exerce o poder? Onde o exerce? Atualmente se sabe, mais ou menos, quem explora, para onde vai o lucro, por que mãos ele passa e onde ele se reinveste, mas o poder... Sabe-se muito bem que não são os governantes que o detêm. Além disso, seria necessário saber até onde se exerce o poder, através de que revezamentos e até que instâncias, freqüentemente ínfimas, de controle, de vigilância, de proibições, de coerções. (Foucault, 2002, p. 75)

Esse grupos, em consonância com o que pensa Foucault, possuem também sempre um líder, liderança essa cujo exercício tende a se transformar em relação de poder e dominação. Essa dominação e 
esse poder, pode-se pensar a partir de Weber, tende a coincidir mais com o que esse autor chamou de dominação do tipo carismática, seja porque a formação de grupos acontece como uma forma dos indivíduos fugirem do ambiente familiar, fundado em laços tradicionais, procurando algo fora desses, que lhes envolva em laços com caráter extracotidiano e representa uma relação estritamente pessoal, ligada à validade carismática de determinadas qualidades pessoais e à prova destas (Weber, 1994). ${ }^{8}$

Assim identificados, os contornos desses grupos parecem ser mais tênues que aqueles fundados numa causa, pois que sua consolidação institucional, apenas na margem, assume o caráter formal, quando aí o poder e a dominação tendem a se rotinizar, prevalecendo suas regras informais, mais ou menos imprecisas, mas presentes e constitutivas das relações que os indivíduos mantêm em sociedade. Assim, é possível falar que tais grupos existem desde sempre por serem a forma predominante de mediação do sujeito com o todo social, mesmo nas comunidades tradicionais, mas sobretudo em espaços urbanizados de grande vulto.

Fundados, assim, na identificação social, na união de iguais, esses grupos se valem de um conjunto de espaços institucionalizados, como bares, restaurantes, praças de esportes, calçadas, ambientes de trabalho e estudo. Podem até vir a formalmente se institucionalizar, mas essa é a exceção, não a regra. As relações que mantêm são, fundamentalmente, relações de poder, assentadas numa forma de direito e de conhecimento específicos. A forma de poder que se exerce no que estamos designando como Espaço Grupal é a desfiliação; sua forma de direito predominante é o direito social-grupal e sua forma epistemológica prevalecente é o senso comum, que se orientam em função de uma dinâmica de desenvolvimento específica: $a$ maximização do pertencimento e do carisma.

No que respeita à forma de poder, a troca desigual se estabelece entre os líderes, interessados na perpetuação do grupo e o restante de seus membros, interessados no status do pertencimento como forma de viabilização das suas respectivas inserções sociais. No bojo dessa troca, estabelece-se um conjunto de relações, que tendem a se instituir 
informalmente, as quais conformam, da mesma forma que nos demais espaços estruturais, um conjunto de "procedimentos regularizados $e$ de padrões normativos considerados justificáveis num dado grupo social, que contribui para a criação e prevenção de litígios e para a sua resolução através de um discurso argumentativo, articulados com a ameaça de força” (Santos, 2001, p. 290). Em outras palavras, as regras e procedimentos comuns, habitus nos termos de Elias, prevalecentes nas configurações que envolvem a formação desses grupos regulam seu funcionamento, pressupondo uma disputa de poder interna, entre os dominantes e dominados e as relações que mantêm com os demais grupos, da mesma espécie ou de espécies diferentes.

\section{Mapa da Estrutura-Ação: o espaço grupal}

\begin{tabular}{|c|c|c|c|c|c|c|}
\hline $\begin{array}{c}\text { Dimensões/ } \\
\text { Espaços } \\
\text { Estruturais }\end{array}$ & $\begin{array}{c}\text { Unidade de } \\
\text { Prática } \\
\text { Social } \\
\end{array}$ & Instituições & $\begin{array}{l}\text { Dinâmica de } \\
\text { Desenvolvi- } \\
\text { mento }\end{array}$ & $\begin{array}{l}\text { Forma } \\
\text { de } \\
\text { Poder }\end{array}$ & $\begin{array}{c}\text { Forma } \\
\text { de } \\
\text { Direito }\end{array}$ & $\begin{array}{c}\text { Forma } \\
\text { Epistemológica }\end{array}$ \\
\hline $\begin{array}{l}\text { Espaço } \\
\text { Grupal }\end{array}$ & $\begin{array}{c}\text { Identifica- } \\
\text { ção social; } \\
\text { união de } \\
\text { iguais }\end{array}$ & $\begin{array}{c}\text { Bares, } \\
\text { restaurantes, } \\
\text { praças } \\
\text { esporte, } \\
\text { calçadas, } \\
\text { ambientes } \\
\text { de } \\
\text { trab./estudo }\end{array}$ & $\begin{array}{l}\text { Maximização } \\
\text { do } \\
\text { pertencimento } \\
\text { e do } \\
\text { carisma }\end{array}$ & $\begin{array}{l}\text { Desfi- } \\
\text { liação }\end{array}$ & $\begin{array}{l}\text { Direito } \\
\text { social- } \\
\text { grupal }\end{array}$ & $\begin{array}{l}\text { Senso } \\
\text { comum }\end{array}$ \\
\hline
\end{tabular}

A forma de conhecimento neles prevalecente é o senso comum. Senso comum ao grupo, que envolve suas respectivas concepções de mundo, uma determinada leitura da história e uma expectativa com relação ao futuro. É, como todas as formas de senso comum, um conhecimento fragmentado, que oculta mais que ilumina, não disposto a ser colocado à prova, caracterizado por um raciocínio circular e que tem por trás relações de poder, o poder que, de uma forma geral, se exerce em torno dos grupos, nos espaços grupais que conformam as sociedades.

Assim, da mesma forma que os sujeitos individualizados, as famílias, as comunidades, os mercados, as unidades produtivas, os Estados ou ainda as organizações mundiais, o funcionamento e a dinâmica dos grupos nas estruturas sociais aos quais aqui se refere 
não podem ser pensadas isoladamente, senão nas suas relações com as demais instâncias da realidade. É nesse sentido que Elias \& Scotson (2000) pensam o funcionamento que se estabelece entre os grupos estabelecidos e os outsiders:

Como indica o estudo de Winston Parva, o grupo estabelecido tende a atribuir ao conjunto do grupo outsider as características 'ruins' de sua porção 'pior' - de sua minoria anômica. Em contraste, a autoimagem do grupo estabelecido tende a se modelar em seu setor exemplar, mais 'nômico' ou normativo - na minoria de seus 'melhores' membros. Essa distorção pars pro toto, em direções opostas, faculta ao grupo estabelecido provar suas afirmações a si mesmo e aos outros; há sempre algum fato para provar que o próprio grupo é ‘bom' e que o outro é 'ruim'. (Elias \& Scotson, 2000, p. 22, 23)

Dessa forma, o estigma é a maneira característica dos grupos se relacionarem e se diferenciarem, rotulando os demais em nome do que se considera ser bom e ruim. Ele se funda, por outro lado, no habitus característico de cada grupo e acaba por servir de critério através do qual seus membros se diferenciam e se utilizam na disputa pelo controle das oportunidades de poder: os instrumentos com os quais se exerce a violência física; os caminhos por onde flui parte da riqueza financeira; os signos com os quais se representa a realidade. Decorre daí que as relações entre os membros de um mesmo grupo e entre grupos se estabelece como uma disputa pelo poder. Contudo, o poder aí não está relacionado apenas à representação e à inserção social do sujeito: está fundado na garantia dessa representação e nessa necessidade de inserção social, e tende a caminhar no sentido do controle de instituições que, na concepção de seus membros, os qualificam para tanto.

Por fim, a tensão entre regulação e emancipação também pode ser vista a partir da análise do espaço grupal, como aqui se propõe. Caberia então a pergunta: em que medida a crise paradigmática vem alterando as relações que se estabelecem nos grupos e entre os grupos? É verdade que ela sugere que outro tipo de conduta ética entre os grupos tende a se estabelecer, sobretudo com a maior difusão de informações, como nos diz Castells e, possibilitando ainda a formação de outros grupos, que não os convencionais: os de internautas, por exemplo. 
Interessante, nesse sentido, será fazer referência ao filme Denise está chamando, no qual um grupo de internautas é levado ao limite de temer o estabelecimento de relações pessoais senão aquelas constituídas por meio eletrônico, inclusive relações sexuais. Mas, haveremos de convir que estabelecer relações dessa forma não implica um processo de emancipação, senão o estabelecimento de relações reguladas da forma convencional.

Pode-se também dizer, nesse mesmo sentido, que novos grupos tendem a se formar em função de questões objetivas, relacionadas à reprodução material das pessoas. Isto é, as amizades passam a possuir interesses outros que não aqueles que se estabelecem a partir da dinâmica grupal das sociedades. Estamos falando aqui de interesses econômicos, relacionados à disputa pelo capital circulante, isto é, pelo controle de instituições por onde fluem partes da riqueza financeira. Mas isso apenas objetiva um pouco mais as relações entre os grupos, sem tirar seu caráter regulacionista.

Talvez, as relações que se estabelecem entre os grupos numa dada sociedade sejam muito mais consolidadas do que nos parece, de maneira equivalente àquelas concernentes aos espaços domésticos. Contudo, de um ponto de vista emancipatório, é possível pensar em tornar tais relações mais democráticas e mais sinceras. Isso sim é diferente e tende a estabelecer um novo padrão de regulação das relações que ocorrem no espaço grupal.

\section{Conclusão}

Buscou-se, aqui, demonstrar a originalidade da contribuição de Boaventura de Souza Santos no contexto do vácuo teórico que passou a existir no âmbito das Ciências Sociais, dada a crise paradigmática que se instalou sobretudo a partir da eclosão de uma série de transformações que marcaram os últimos cinqüenta anos. Essa contribuição caminha no sentido de possibilitar uma maior aproximação da realidade e da compreensão dos processos que se encontram em curso. É isso que possibilita o Mapa da Estrutura- 
Ação das Sociedades Capitalistas no Espaço Mundial. Posto isto, o presente trabalho também contém uma proposta de inclusão, no Mapa da Estrutura-Ação, de dois outros espaços estruturais - os espaços do sujeito e grupal.

Fundamentalmente, procurou-se argumentar que, dos processos gerais em curso também fazem parte as dinâmicas de desenvolvimento inerentes ao indivíduo, sujeito e protagonista de microprocessos históricos, e aos grupos que esses sujeitos conformam: configurações sem as quais não se consegue compreender as estruturas sociais e seus processos de reprodução e transformação.

Com base em Elias, que parece ter se antecipado à própria crise paradigmática, não se pode negligenciar as histórias das pessoas nem dos grupos que elas formam, ao se procurar compreender os processos de conformação e transformação das sociedades. O preço dessa negligência é a simples troca do indivíduo universal da Escolástica pelo indivíduo ideal do Iluminismo. Dessa forma, se, de um lado, não se pode reduzir os processos históricos mais gerais ao somatório das histórias individuais, também não se pode, por outro, pretender a compreensão daqueles sem que se tenha presente as pessoas e os grupos, as relações que mantêm consigo mesmo, com o ambiente social e natural de que fazem parte e suas respectivas histórias.

Esse Mapa, por fim, permite perceber os processos em curso de construção do espaço social de forma compartilhada, a partir de espaços estruturais distintos, com suas respectivas dinâmicas de desenvolvimento. Alcança-se, nesse sentido, duas possibilidades de naturezas distintas. Isto é, além daquela relativa ao término do monopólio da percepção predominante, que privilegia ora o espaço da cidadania, ora o espaço mundial e seus desdobramentos em termos dos espaços do mercado e da produção, possibilita também que se pense na construção de estratégias socioeconômicas de desenvolvimento e/ou de transformação social, que possuem outras entradas, como aquelas relacionadas aos espaços do sujeito, doméstico, do grupo e da comunidade, com implicações sobre os espaços da produção e do mercado. 


\section{Mapa de estrutura-ação estendido das sociedades capitalistas no sistema mundial}

\begin{tabular}{|c|c|c|c|c|c|c|}
\hline $\begin{array}{c}\text { Dimensões } \\
\text { /Espaços } \\
\text { Estruturais }\end{array}$ & $\begin{array}{c}\text { Unidade } \\
\text { de Prática } \\
\text { Social }\end{array}$ & Instituições & $\begin{array}{c}\text { Dinâmica } \\
\text { de } \\
\text { Desenvolvi- } \\
\text { mento }\end{array}$ & $\begin{array}{c}\text { Forma } \\
\text { de } \\
\text { Poder }\end{array}$ & $\begin{array}{c}\text { Forma } \\
\text { de } \\
\text { Direito }\end{array}$ & $\begin{array}{c}\text { Forma } \\
\text { Epistemo- } \\
\text { lógico }\end{array}$ \\
\hline $\begin{array}{c}\text { Espaço do } \\
\text { Sujeito }\end{array}$ & $\begin{array}{c}\text { Relação do } \\
\text { indivíduo } \\
\text { com ele } \\
\text { mesmo }\end{array}$ & Indivíduo & \begin{tabular}{|c|} 
Maximiza- \\
ção da aute \\
imagem e \\
estima
\end{tabular} & Culpa & $\begin{array}{l}\text { Auto- } \\
\text { censura }\end{array}$ & $\begin{array}{l}\text { Auto- } \\
\text { conheci- } \\
\text { mento }\end{array}$ \\
\hline $\begin{array}{c}\text { Espaço } \\
\text { Doméstico }\end{array}$ & $\begin{array}{c}\text { Diferença } \\
\text { sexual e } \\
\text { geracional }\end{array}$ & $\begin{array}{c}\text { Casamento, } \\
\text { família e } \\
\text { parentesco }\end{array}$ & $\begin{array}{l}\text { Maximiza- } \\
\text { ção da } \\
\text { afetividade }\end{array}$ & Patriarcado & $\begin{array}{c}\text { Direito } \\
\text { doméstico }\end{array}$ & $\begin{array}{c}\text { Familismo } \\
\text { cultura } \\
\text { familiar }\end{array}$ \\
\hline $\begin{array}{l}\text { Espaço } \\
\text { Grupal }\end{array}$ & $\begin{array}{c}\text { Identifica- } \\
\text { ção social; } \\
\text { união de } \\
\text { iguais }\end{array}$ & \begin{tabular}{|c|} 
Bares, \\
restaurantes \\
praças \\
esporte, \\
calçadas, \\
ambientes \\
de trabalho/ \\
estudo
\end{tabular} & \begin{tabular}{|} 
Maximiza- \\
zação do \\
perten- \\
cimento
\end{tabular} & Desfiliação & $\begin{array}{c}\text { Direito } \\
\text { social - } \\
\text { grupal }\end{array}$ & $\begin{array}{l}\text { Senso } \\
\text { comum }\end{array}$ \\
\hline $\begin{array}{l}\text { Espaço da } \\
\text { Produção }\end{array}$ & $\begin{array}{c}\text { Classe e, } \\
\text { natureza } \\
\text { enquanto } \\
\text { natureza } \\
\text { capitalista }\end{array}$ & $\begin{array}{l}\text { Fábrica e } \\
\text { empresa }\end{array}$ & $\begin{array}{c}\text { Maximiza- } \\
\text { ção do lucro } \\
\text { e da } \\
\text { degradação } \\
\text { da natureza }\end{array}$ & $\begin{array}{l}\text { Exploração } \\
\text { e natureza } \\
\text { capitalista }\end{array}$ & $\begin{array}{l}\text { Direito } \\
\text { da } \\
\text { produção }\end{array}$ & $\begin{array}{c}\text { Produtivis- } \\
\text { mo, tecno- } \\
\text { logismo, } \\
\text { formação } \\
\text { profissiona } \\
\text { e cultura } \\
\text { empresarial }\end{array}$ \\
\hline $\begin{array}{l}\text { Espaço de } \\
\text { Mercado }\end{array}$ & $\begin{array}{c}\text { Cliente - } \\
\text { consumidor }\end{array}$ & Mercado & \begin{tabular}{|c|} 
Maximiza- \\
ção da \\
utilidade e \\
da mercado- \\
rição das \\
necessi- \\
dades \\
\end{tabular} & $\begin{array}{c}\text { Fetichismo } \\
\text { das } \\
\text { mercadorias }\end{array}$ & $\begin{array}{l}\text { Direito } \\
\mathrm{da} \\
\text { troca }\end{array}$ & $\begin{array}{l}\text { Consumis- } \\
\text { mo e } \\
\text { cultura de } \\
\text { massa }\end{array}$ \\
\hline $\begin{array}{l}\text { Espaço da } \\
\text { comuni- } \\
\text { dade }\end{array}$ & $\begin{array}{l}\text { Etnicidade, } \\
\text { raça, nação, } \\
\text { povo, } \\
\text { religião }\end{array}$ & $\begin{array}{l}\text { Comuni- } \\
\text { dade, } \\
\text { vizinhança, } \\
\text { região, } \\
\text { organiza- } \\
\text { ções } \\
\text { populares } \\
\text { de base, } \\
\text { Igrejas. } \\
\end{array}$ & $\begin{array}{l}\text { Maximiza- } \\
\text { ção da } \\
\text { Identidade }\end{array}$ & $\begin{array}{l}\text { Diferencia- } \\
\text { ção desigual }\end{array}$ & $\begin{array}{l}\text { Direito da } \\
\text { comuni- } \\
\text { dade }\end{array}$ & $\begin{array}{l}\text { Conheci- } \\
\text { mento local, } \\
\text { cultura da } \\
\text { comuni- } \\
\text { dade e } \\
\text { tradição. }\end{array}$ \\
\hline $\begin{array}{l}\text { Espaço da } \\
\text { Cidadania }\end{array}$ & Cidadania & Estado & $\begin{array}{l}\text { Mazimiza- } \\
\text { ção da } \\
\text { lealdade }\end{array}$ & Dominação & $\begin{array}{l}\text { Direito } \\
\text { territorial } \\
\text { (estadual) }\end{array}$ & $\begin{array}{c}\text { Nacionalis- } \\
\text { educacional } \\
\text { e cultural, } \\
\text { cultura } \\
\text { cívica }\end{array}$ \\
\hline $\begin{array}{l}\text { Espaço } \\
\text { Mundial }\end{array}$ & $\begin{array}{l}\text { Estado- } \\
\text { Nação }\end{array}$ & \begin{tabular}{|c|} 
Sistema \\
interestadual \\
organismos, \\
e associação \\
internacional, \\
tratados \\
internacionais
\end{tabular} & $\begin{array}{l}\text { Mazimiza- } \\
\text { ção da } \\
\text { eficácia }\end{array}$ & $\begin{array}{c}\text { Troca } \\
\text { desigual }\end{array}$ & $\begin{array}{l}\text { Direito } \\
\text { sistêmico }\end{array}$ & $\begin{array}{c}\text { Ciência, } \\
\text { progresso } \\
\text { universalís- } \\
\text { tico, cultural } \\
\text { global }\end{array}$ \\
\hline
\end{tabular}


Uma política, por exemplo, que tencione fomentar o associativismo e/ou as organizações de mulheres, no âmbito das comunidades, poderá ter efeitos significativos nas relações de poder prevalecentes nos espaços doméstico e da produção e, em conseqüência, sobre os espaços do mercado e da cidadania, alterando o equilíbrio de forças mais ou menos instável das instituições prevalecentes nesses espaços e, em conseqüência, transformando substancialmente os processos de construção social no âmbito local e regional. O estudo aplicado tanto das contribuições quanto da análise aqui contida, contudo, constitui-se ainda num desafio com muitas possibilidades ainda a serem exploradas.

\section{Notas}

1 Para o autor, campo constitui-se num espaço estruturado e interdependente em relação a outros campos, sob a hegemonia mais ou menos evidente do campo econômico, onde os atores disputam a representatividade simbólica que dá significado a esse espaço especifico. Os atores dominantes são os possuidores de maior capital simbólico e, na sua relação com os dominados e esses, na sua relação com os primeiros, ao mesmo tempo, legitimam o campo de disputa e desenvolvem o habitus, isto é, conjunto de práticas sociais que lhes são específicas.

2 Além dessa dimensão externa, digamos assim, relativa à crise paradigmática que vive a Ciência Moderna, deve também ser considerada sua dimensão interna: $\mathrm{O}$ princípio da causalidade e o postulado do determinismo universal não são demonstráveis (E. Morin, citado por Vasconcelos, 2002, p. 46). Ver também Bruseke (1993).

3 Ver, a esse respeito, Fiori (1999).

4 Estamos aqui nos valendo de Elias (2001a, 2001b) e principalmente Elias $(1991,1994)$ e Chartier (2001).

5 A contraposição é devida a Albert Hirschman, citado por Bianchi (1989).

6 Há, porém, o cuidado de discernir escolha de decisão: (...) a abertura da vida social à tomada de decisão não deve ser identificada 'ipso facto' com o pluralismo; é também um meio de poder e estratificação (Giddens, 1997, p. 95, 96). 
7 Sobre a importância da fofoca e do estigma na constituição e reprodução de grupos estabelecidos e outsiders, ver Elias \& Scotson (2000).

8 Mesmo apontando limites para a compreensão da "sociedade dos indivíduos" a partir dos tipos ideais weberianos, Elias (2001, p. 52 e segs) formula uma análise da importância desse aspecto das relações na constituição dos grupos.

Abstract: This paper is an attempt to reflect upon Boaventura de Sousa Santos' ideas, especially the ones which shaped his work "A crítica da razão indolente: contra o desperdício da experiência", having, as a theoretical support, Norbert Elias' sociological construct. In doing so, we mainly argue for the inclusion of two structural spaces, namely Espaço do Sujeito and Espaço Grupal (individual space and group space, respectively ) in a social "map" devised by Santos, who named it as Mapa da Estrutura-Ação das sociedades capitalistas no espaço mundial (Structure-Action Map of the capitalist societies in the world context). The need for the inclusion of these new "spaces" is justified by the argument that the individual, as we know him, was born together with modern times. Due to the possibilities of keeping a dialogue with himself as a subject, the individual can also be perceived as a structural space, controlled by both regulation and social emancipation forces developed by Santos. The social group, on the other hand, has its own dynamics, which cannot be totally apprehended neither by the domestic space nor by the community space. Having these considerations in mind, the author develops his contribution, from what he calls paradigmatic transition, achieving three aims: first, he analyses and brings about the main features of Norbert Elias' work; second, he carries out a brief incursion into Elias' sociology, and finally, he proposes the inclusion of the subject and group spaces as relevant categories that will help to grasp the reality in movement. The conclusion does not only recall the first discussion, but it also points out the role of the two structural spaces proposed and the whole map organization as well, so that one can have a better understanding of the current processes and the construction of strategies, which lead to social transformation.

Keywords: paradigmatic transition; structure-action map, Norbert Elias, Sociology, subject space, group space.

Résumé: Ce travail cherche un dialogue avec l'oeuvre de Boaventura de Souza Santos, notamment en ce qui concerne son apport inclus 
dans "A crítica da razão indolente: contra o desperdício da experiência". Ce que l'on propose, surtout en se fondant sur Norbert Elias, c'est l'inclusion, dans le Tableau de la Structure-Action des sociétés capitalistes dans le domaine mondial, des deux autres espaces structurels qui n'y sont pas: l'espace de l'individu et l'espace groupal. Notre argument repose sur le fait que, l'individu tel qu'il est connu aujourd'hui, s'établit dans une institution qui est née avec la modernité. Celui-là, en raison de la possibilité du dialogue qu'il a avec soi-même, en tant qu'individu, peut aussi être vu comme un espace structurel sujet à l'action des forces de réglementation et d'émancipation socilale évoquées par Santos. Le groupe social, à son tour, a sa propre dynamique qui ne peut être tout à fait saisie ni par l'espace domestique ni par l'espace communautaire. Dans ce sens, à partir de ce que l'auteur nomme transition paradigmatique, ce travail fait une analyse et un exposé des lignes principales de sa contribution, pour faire, ensuite, une breve incursion dans la sociologie de Norbert Elias et proposer l'inclusion de l'espace de l'individu et de l'espace du groupe en tant que des domaines relevables pour l'appréhension de la réalité en mouvement. À la conclusion, l'on reprendra la discussion initiale en soulignat le rôle de ces deux espaces structurels proposés ainsi que le Tableau de la Structure-Action des Sociétés Capitalistes en vue de la compréhension des processus en cours et de la constitution des stratégies pour le changement social.

Mots-Clés: transition paradigmatique, tableau de la structure-action, Sociologie, Norbert Elias, espace de l'individu, espace groupal.

\section{Referências bibliográficas}

BIANCHI, A. M. A pré-história da Economia. Campinas: Hucitec, 1989.

BOURDIEU, P. O poder simbólico. Lisboa: Difel, Bertrand Brasil, 1989.

BRUSEKE, F. Josef. Caos e ordem na Teoria Sociológica. Revista Brasileira de Ciências Sociais, São Paulo, v. 8, jun. 1993.

CAPRA, F. O ponto de mutação. São Paulo: Cultrix, 1982.

CASTELLS, M. O poder da identidade. São Paulo: Paz e Terra, 1999.

CHARTIER, R. Prefácio. In: ELIAS, N. A sociedade de corte. Rio de Janeiro: Jorge Zahar, 2001. 
DOMINGUES, J. M. Criatividade social, subjetividade coletiva e a modernidade brasileira contemporânea. Rio de Janeiro: Contra-Capa Livraria, 1999.

ELIAS, Norbert. Quést-ce que la sociologie. Paris: Éditions de L'aube, 1991. . A sociedade dos indivíduos. Rio de Janeiro: Jorge Zahar, 1994. . A sociedade de corte. Rio de Janeiro: Jorge Zahar, 2001a. . Norbert Elias por ele mesmo. Rio de Janeiro: Jorge Zahar, 2001b.

ELIAS, Norbert; SCOTSON, J. L. Os estabelecidos e os outsiders. Rio de Janeiro: Jorge Zahar, 2000.

FIORI, J. L. (Org.). Estados e moedas no desenvolvimento das Nações. Petrópolis: Vozes, 1999.

FOUCAULT, M. A Microfísica do poder. Rio de Janeiro: Graal, 2002.

GIDDENS, A. A vida em uma sociedade pós-tradicional. In: BECK et al. Modernização Reflexiva: tradição e estética na ordem social moderna. São Paulo: UNEP, 1997.

MANCEBO, Deise. Modernidade e produção de subjetividades: um breve percurso histórico. Psicologia: Ciência e Profissão, Brasília, v. 22, n. 1, 2002.

SANTOS, B. S. Crítica à razão indolente: contra o desperdício da experiência. São Paulo: Cortez, 2001.

VASCONCELOS, M. J. E. Pensamento sistêmico: o novo paradigma da ciência. Campinas: Papirus, 2002.

WEBER, M. Os três tipos de dominação. In: . Economia e sociedade. Brasília: UnB, 1994. 